\title{
EVALUATION OF DESTAINING METHODS IN DNA GYTO- FLUOROMETRY OF THE WRIGHT-GIEMSA STAINED NORMAL AND LEUKEMIC GELLS
}

\author{
Chimiro SHimaZAKI, Shinobu NAKANISHi, Harue HARUYAMA, \\ Takuji ISEMURA, Masao NAKAGAWA and Hamao IJICHI
}

\author{
2nd Department of Internal Medicine, Kyoto Prefectural \\ University of Medicine, Kyoto 602
}

Received for publication May 6, 1982 and in revised form September 10, 1982

\begin{abstract}
In order to determine DNA content of leukemic cells by means of cytofluorometry, morphological identification of cells on the Wright-Giemsa (W-G) stained smear is required prior to Feulgen nuclear reaction. The complete removal of $W-G$ staining is an essential problem to perform accurate DNA cytofluorometry. This paper reports the most reliable destaining method which preserves the proportionality between fluorescence intensity and DNA content based on a comparative study of several conventional destaining methods.

The destaining method with $5 \%$ TCA followed by $100 \%$ methanol is considered to be the most practical and reliable method to remove $W$-G staining on the accurate DNA cytofluorometry of the cells identified by W-G stain.
\end{abstract}

The DNA content of various benign or malignant tumor cells has been measured by means of microspectrophotometric methods and aneuploid or polyploid DNA distribution patterns of neoplastic cells have been reported in solid tumors, while the diploid or near-diploid patterns have been reported to be dominant in leukemic cells. (5)

However, there have been some problems in the measurement of DNA content by these microspectrophotometric methods such as distributional errors and nonspecific light loss due to light refraction and scattering in the object.

However, with cytofluorometry these problems become negligible and other basic problems in this fluorescence method, such as primary fluorescence, fluorescence fading and non-specific dye-binding, have been solved by recent technical advances. The post-irradiation method $(8,11)$ eliminates the primary fluorescence and stabilizes the specific nuclear fluorescence, and the post fixation with absolute methanol followed by embedding with nonfluorescent resin $(14,15)$ increases the stability of fluorescence, and azocarmin G staining $(23,24)$ blocks the non-specific dye-binding in acriflavine-Feulgen reaction on isolated cells from paraffin-embedded tissue sections. These new techniques have enabled us to measure DNA content more accurately.

In application of this cytofluorometric method to leukemic cells, it is difficult to differentiate these cells from other immature cells only by nuclear fluorescence 
under the cytofluorometer, so it is necessary to identify morphologically these cells by Wright-Giemsa (W-G) staining and cytofluorometric analysis should be performed after removal of the W-G staining.

This paper reports the evaluation of a few destaining methods and the most suitable method which does not affect the proportionality between fluorescence intensity and DNA content.

\section{MATERIALS AND METHODS}

\section{1) Destaining}

Smear preparations of human peripheral blood or imprint preparations of hepatocytes from DBA/2 mouse of 8 months were fixed with $100 \%$ methanol for $30 \mathrm{~min}$ and used as non-W-G-stained control, to compare with these preparations which were first stained with $\mathrm{W}-\mathrm{G}$ and destained by the following methods: (1) $5 \%$ trichloroacetic acid (TCA) for $30 \mathrm{sec}$ at room temperature followed by $100 \%$ methanol for $30 \mathrm{~min}$ at room temperature, the method reported by Wickramasinghe et al. (25), (2) $100 \%$ methanol for $10 \mathrm{hr}$ at $37^{\circ} \mathrm{C}$, (3) $50 \%$ ethanol for $3 \mathrm{hr}$ at $37^{\circ} \mathrm{C}$ followed by $100 \%$ methanol for $3 \mathrm{hr}$ at $37^{\circ} \mathrm{C}$.

\section{2) Fluorescence staining}

After destaining the W-G dye, Azocarmin G-acriflavine-Feulgen double staining was performed as described previously $(23,24)$. Briefly, all specimens were stained with $0.02 \%$ azocarmin $\mathrm{G}$ solution with the addition of $0.1 \%$ acetic acid for $90 \mathrm{sec}$ at $25^{\circ} \mathrm{C}$ in order to block the background fluorescence. All the slides were washed in running water for $10 \mathrm{~min}$ and hydrolyzed in $1 \mathrm{~N} \mathrm{HCl}$ for $5 \mathrm{~min}$ at $60^{\circ} \mathrm{C}$. After Feulgen hydrolysis, the slides were all washed in ice-cold $0.1 \mathrm{~N} \mathrm{HCl}$ to stop acid hydrolysis. The Feulgen nuclear reaction was carried out with $0.001 \%$ acriflavine Schiff-reagent for $10 \mathrm{~min}$ at $7^{\circ} \mathrm{C}$.

After 3 rinses of $2 \mathrm{~min}$ in sulfur dioxide solution, the slides were washed thoroughly in running water for $10 \mathrm{~min}$, air-dried and embedded in non-fluorescent resin (Entellan; Merck, West Germany). In order to eliminate primary fluorescence and stabilize the specific fluorescence in the specimens, all the slides were post-irradiated with violet excitation light for acriflavine $(\lambda \max =437 \mathrm{~nm})$ according to the method reported by Fujita and Fukuda $(8,11)$.

3) Cytofluorometry

Cytofluorometric DNA measurement was performed with an Olympus MMSPRF. The following set of optical filters was used for cytofluorometric quantification of acriflavine-DNA; interference excitation filter $(\lambda \max =437 \mathrm{~nm})$, dichroic mirror (DM-455), and interference barrier filter $(\lambda \max =520 \mathrm{~nm})$. For the observation of cytoplasmic fluorescence of azocarmin G, a set including an interference excitation filter $(\lambda \max =543 \mathrm{~nm})$, dichroic mirror (DM-580), and optical glass filter $(\lambda \max =600 \mathrm{~nm})$ was used.

4) Application to human leukemic cell

Leukemic cells of patient with chronic myelogenous leukemia (CML) were utilized for this study. These cells at the blastic phase were identified by W-G 
stain and after destaining of W-G dye by method (1), these were stained with acriflavine-Schiff reagent after azocarmin G blocking. The preparation was further post-irradiated and cytofluorometric DNA measurement was performed as described above.

\section{RESULTS}

A) Human segmented neutrophil

The results of cytofluorometric DNA determinations of 100 human segmented neutrophils with each destaining method are shown in Table 1.

In methods (1) and (2), acriflavine-Feulgen staining with or without blocking the non-specific dye-binding by azocarmin $G$ was performed.

The mean DNA value and standard deviation of control cells was $20.04 \pm 0.59$ in arbitrary unit of fluorescence intensity and the coefficient of variation (CV) was the lowest with a value of 2.69. CV of this determination by method (1) with azocarmin $\mathrm{G}$ staining is the most approximate to control cells with a value of 2.81 . From these observations, destaining method (1) was thought to be the most suitable in practical use.

B) Mouse hepatocyte

In order to examine the effects of each destaining method on the proportionality between fluorescence intensity and DNA content, mouse hepatocytes were used.

TABLE 1. DNA content of human segmented neutrophils at various destaining conditions $(n=100)$

\begin{tabular}{ccccc}
\multicolumn{2}{c}{ Pretreatment } & Acriflavine-Felugen & $\begin{array}{c}\text { DNA content } \\
\text { (mean } \pm \text { S.D.) }\end{array}$ & C.V. \\
Destaining & Azocarmin-G & & & \\
\hline$(-)$ & $(+)$ & $(+)$ & $20.04 \pm 0.54$ & 2.69 \\
\hline TCA & $(+)$ & $(+)$ & $20.04 \pm 0.56$ & 2.81 \\
& $(-)$ & $(+)$ & $20.15 \pm 1.00$ & 4.95 \\
M-OH & $(+)$ & $(+)$ & $20.52 \pm 0.86$ & 4.21 \\
& $(-)$ & $(+)$ & $20.35 \pm 0.89$ & 4.37
\end{tabular}

Numbers indicate arbitrary unit of fluorescence intensity. TCA; $5 \%$ trichloroacetic acid followed by $100 \%$ methanol $\mathrm{M}-\mathrm{OH} ; 100 \%$ methanol SD; standard deviation $\mathrm{CV}$; coefficient of variation.

TABLE 2. DNA content of mouse hepatocytes at various destaining conditions

\begin{tabular}{ccccc} 
& control & TCA $\rightarrow \mathrm{M}-\mathrm{OH}$ & $\mathrm{M}-\mathrm{OH}$ & $\mathrm{E}-\mathrm{OH} \rightarrow \mathrm{M}-\mathrm{OH}$ \\
\hline $\mathrm{C}$ & $20.08 \pm 0.89$ & $20.98 \pm 1.34$ & $20.23 \pm 2.33$ & $20.47 \pm 1.22$ \\
$4 \mathrm{C}$ & $40.41 \pm 1.08$ & $39.43 \pm 1.98$ & $39.65 \pm 2.91$ & $39.69 \pm 2.24$ \\
$8 \mathrm{C}$ & $79.46 \pm 2.20$ & $79.05 \pm 2.59$ & $76.51 \pm 3.46$ & $79.26 \pm 4.55$
\end{tabular}

(mean value \pm standard deviation in arbitrary unit) $2 \mathrm{C}, 4 \mathrm{C}$ and $8 \mathrm{C}$ represent diploid, tetraploid and octaploid class of mouse hepatocyte, respectively. 

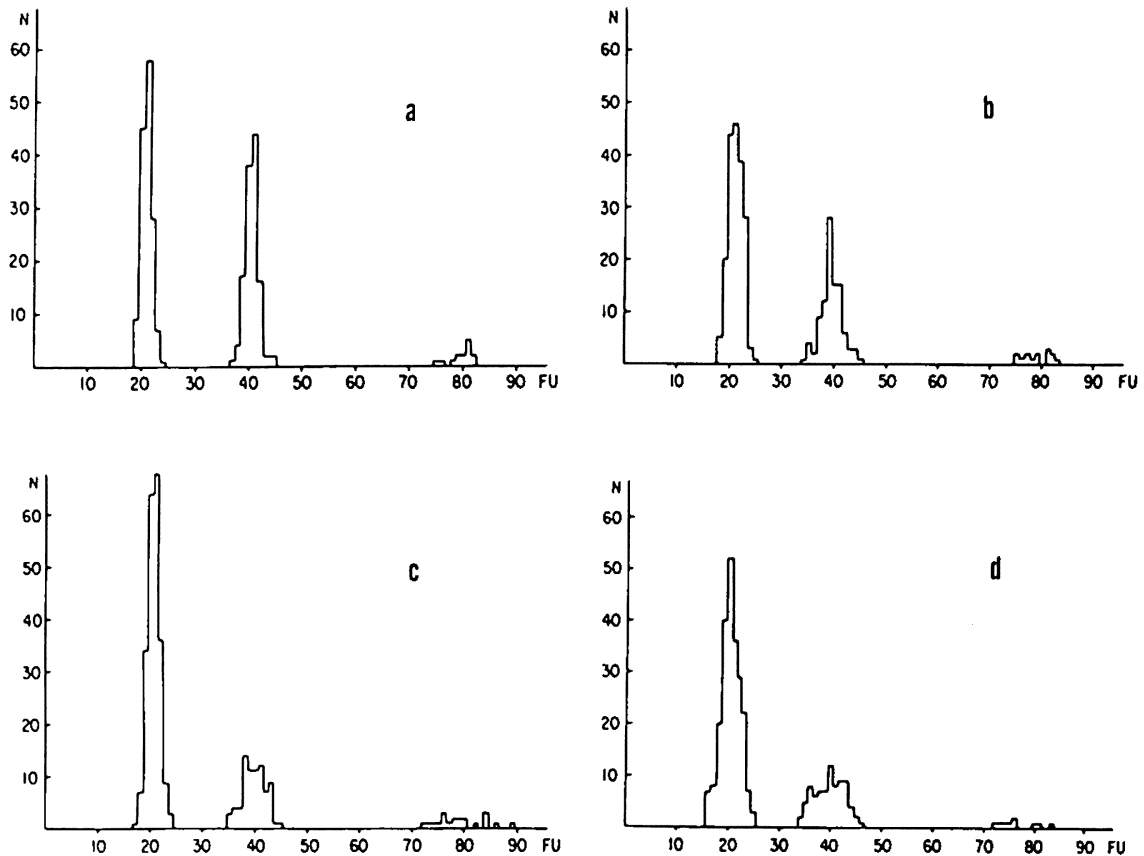

Fig. 1. DNA cytofluorometric determination on mouse hepatocytes. N; number of cells measured, FU; fluorescence intensity of Feulgen DNA in arbitrary unit. a) control specimen of mouse hepatocyte without Wright-Giemsa stain. b) mouse hepatocyte destained with 5\% TCA followed by $100 \%$ methanol. c) mouse hepatocyte destained with $100 \%$ methanol. d) mouse hepatocyte destained with $50 \%$ ethanol followed by $100 \%$ methanol.

DNA histograms of the control and destained mouse hepatocytes are shown in Fig. 1 and results of these data were summarized in Table 2. The DNA content of control hepatocytes was $20.08 \pm 0.89,40.41 \pm 1.08$, and $79.46 \pm 2.20$ for diploid, tetraploid and octaploid class in arbitrary unit, respectively.

Distribution of DNA contents showed integral values of $2: 4: 8$ and dispersion of each ploidy class was small thereby supporting the accuracy of DNA cytofluorometry.

The DNA content of hepatocytes destained by method (1) (Fig. lb) was $20.98 \pm 1.34,39.43 \pm 1.98$, and $79.05 \pm 2.59$ for diploid, tetraploid and octaploid class in arbitrary unit, respectively and dispersion of each ploidy class was smaller than that destained by method (2) or (3).

Destaining method (2) and (3) were not considered inappropriate for use in DNA cytofluorometry as shown in Table 2, but destaining method (1) was more

FIG. 2. Large leukemic cell appeared in peripheral blood at the blastic phase of chronic myelogenous leukemia. a) Wright-Giemsa stained leukemic cell. b) the same leukemic cell with azocarmin G-acriflavine-Feulgen double staining after destaining by $5 \%$ TCA and methanol. Note the yellowish green fluorescence of acriflavine Feulgen staining in completely dark background at the violet excitation light. c) erythrocyte fluorescence of azocarmin $\mathrm{G}$ emitted at the green excitation light in the same visual field. $\times 1,000$ 


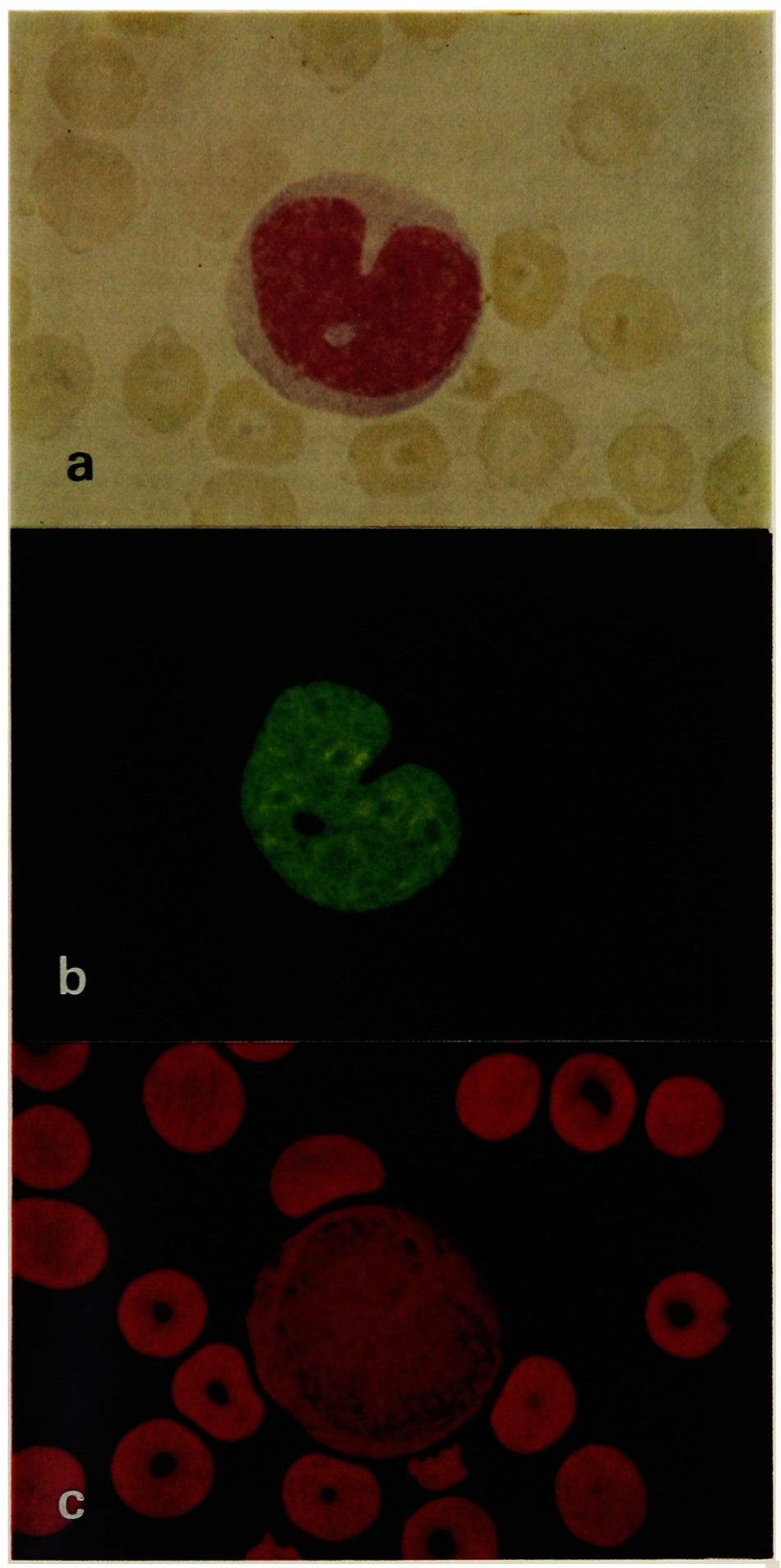




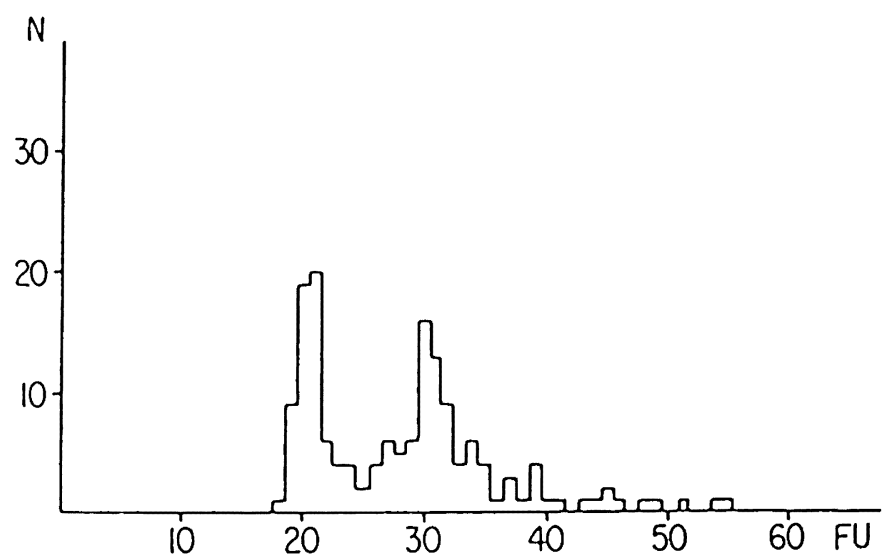

FIG. 3. DNA cytofluorometry on leukemic cells at the blastic phase of chronic myelogenous leukemia. $\mathrm{N}$; number of cells measured, FU; fluorescence intensity of Feulgen DNA in arbitrary unit. Fluorescence intensity of control segmented neutrophil is 20.

preferable than method (2) and (3) because undesirable effects upon the proportionality between fluorescence intensity and DNA content were less and because the time required is much shorter than that of the other two methods.

C) Human leukemic cells

Figure 2a shows an abnormally large leukemic cell which appeared at the blastic phase of a 34 years-old man with chronic myelogenous leukemia. Upon observation by the cytofluorometer, clear specific fluorescence of acriflavine-Feulgen staining was noted in completely dark background at the violet $(\lambda \max =437 \mathrm{~nm})$ excitation (Fig. 2b). The nucleus of this leukemic cell showed a fine chromatin pattern and rounded nucleoli, without destruction of nucleus and extravasation of nuclear substance. Erythrocytes around this cell were not fluorescent. Red cellular fluorescence of azocarmin $G$ emitted at the green $(\lambda \max =543 \mathrm{~nm})$ excitation light is shown in Fig. 2c. These observations indicate that this destaining method with $5 \%$ TCA and 100\% methanol enabled us to carry out DNA cytofluorometry after morphological identification.

This leukemic cell showed a DNA content of 52 in arbitrary unit of fluorescence intensity in contrast to that of segmented neutrophil as 20 in arbitrary unit of fluorescence intensity.

DNA cytofluorometry (Fig. 3) in this case showed an abnormal peak of 3C: DNA value and combined method with ${ }^{3} \mathrm{H}$-thymidine autoradiography (9) demonstrated that these large leukemic cells consisted of a $3 \mathrm{C}$ stem line with scattering up to $6 \mathrm{C}$ DNA value, apparently different from $2 \mathrm{C}$ stem line supposed to be derived from the $\mathrm{Ph}^{\prime}(+)$ clone that had existed in the chronic phase (21).

\section{DISCUSSION}

Many investigators have reported the measurement of DNA content of leukemic cells by microspectrophotometry $(5,6,7,16,17,18,19,26)$, cytofluorometry 
(22), and recently developed flow-cytometric techniques $(1,2,3,4)$.

According to these reports, diploid and near-diploid patterns of DNA content were dominant in leukemia and recently Barlogie et al. $(3,4)$ reported that ploidy abnormality was detected in $15 \%$ of 170 patients with various types of leukemia by flow-cytometry. But the measurement of DNA content of a single leukemic cell which was morphologically identified by Giemsa stain was rarely performed.

In cases of leukemia, in which the cellular components in the bone marrow or peripheral blood are mostly leukemic cells, discrimination of leukemic cells from other immature cells such as promyelocytes does not become a problem but in cases of leukemia such as hypoplastic leukemia in which the number of leukemic cells are small and as erythroleukemia, differentiation of leukemic cells from other cell lines becomes important and morphological identification by Giemsa staining is required in order to delineate leukemic cells as objectives.

Fischer et al. (6) and Foadi et al. (7) reported the measurement of DNA contents of leukemic cells after morphological identification by May-GrünwaldGiemsa stain, but the destaining methods were not described in detail. Queisser et al. (19) reported the DNA contents of leukemic cells using 50\% ethanol for destaining Pappenheim stain. Regarding the erythroid cell lineage, several authors $(10,12,13,25)$ reported the DNA content of a single cell after removal of the Giemsa staining. However, destaining methods have not been standardized yet and furthermore we found the differences in the obtained data depended upon the various destaining methods utilized in these studies. The effects of destaining method on the proportionality between fluorescence intensity and DNA content were not evaluated so far.

These three destaining methods mentioned above were not inappropriate in DNA cytofluorometry but the destaining method with $5 \%$ TCA followed by $100 \%$ methanol reported by Wickramasinghe et al. (25) was more practical and superior to the other two methods with respect to the fact that the effects on the proportionality between fluorescence intensity and DNA content were smaller and that the time required was much shorter.

However this destaining method is not widely used in cytofluorometry. For example, on the preparation treated by this destaining method, erythrocytes assume a green color microscopically and this is supposed to be due to the degeneration of hemoglobin ( $\mathrm{Hb})$ by TCA in red cell, so it is supposed to be inappropriate to use this destaining method in measuring the amount of $\mathrm{Hb}$.

Fukuda et al. (10) reported the measurement of $\mathrm{Hb}$ content on cells after removal of the Giemsa staining by $10 \%$ TCA and $100 \%$ methanol in his first report but in his successive reports $(12,13)$, he used absolute methanol at $37^{\circ} \mathrm{C}$ for $8 \mathrm{hr}$ for destaining. In those reports, he described that complete removal of Giemsa staining was accomplished except for green granular primary fluorescence in eosinophilic myeloid cells by violet excitation.

While the removal of the W-G staining from nucleus and cytoplasm by the method (1) was more complete than the other two methods, it is concluded that the complete removal of the W-G dye by this destaining method will provide more accurate DNA cytofluorometry.

There might be a problem to be considered in treatment with TCA, because TCA acts as a hydrolytic reagent for the Feulgen reaction (20) and an injury of TCA 
to DNA molecule is possible.

However, hydrolysis in Feulgen staining is performed by treatment in $0.25 \mathrm{M}$ $\mathrm{TCA}$ at $65^{\circ} \mathrm{C}$ for $50 \mathrm{~min}$. The present procedure for destaining with $5 \%$ TCA, at room temperature for $30 \mathrm{sec}$ is much milder. It is inferred that the effects of this destaining method on DNA are negligibly small in practical DNA-cytofluorometry and the present study justified this inference. As described above, this destaining method also has the advantage that the time required is much shorter than that required for the other destaining methods.

From these observations, it is concluded that the destaining method with $5 \%$ TCA followed by $100 \%$ methanol is the best way to perform accurate DNA cytofluorometry on the cells identified by W-G stain.

\section{REFERENCES}

1. Andreeff, M., Darzynkiewicz, Z., Sharpless, T. K., Clarkson, B. D. and Melamed, M. R.: Discrimination of human leukemia subtypes by flow cytometric analysis of cellular DNA and RNA. Blood 55; 282-293, 1980.

2. Barlogie, B., Spitzer, G., Hart, J. S., Johnston, D. A., Büchner, T., Schumann, J. and Drewinko, B.: DNA histogram analysis of human hemopoietic cells. Blood 43; 245-258, 1976.

3. Barlogie, B., Hittelman, W., Spitzer, G., Trujillo, J. M., Hart, J. S., Smallwood, L. and Drewinko, B.: Correlation of DNA distribution abnormalities with cytogenetic findings in human adult leukemia and lymphoma. Cancer Res. 37; 4400-4407, 1977.

4. Barlogie, B., Latreille, J., Freireich, E. J., Chi-Tse-Fu, Mellard, D., Meistrich, M. and Andreeff, M.: Characterization of hematologic malignancies by flow cytometry. Blood Cells 6; 719744, 1980.

5. Böhm, N. and Sandritter, W: DNA in human tumors; A cytophotometric study. Curr. Top. Pathol. 60; 151-219, 1975.

6. Fischer, M., Mitrou, P. S. and Hübner, K.: Proliferative activity of undifferentiated cells (blast cells) in preleukemia. Acta haemat. 55; 148-152, 1976.

7. Foadi, M. D., Cooper, E. H. and Hardisty, R. M.: Proliferative activity of leukemic cells at various stages of acute leukemia of childhood. Brit. J. Haemat. 15; 269-281, 1968.

8. Fujita, S. and Fukuda, M.: Irradiation of specimens by excitation light before and after staining with pararosaniline Feulgen; A new method to reduce non-specific fluorescence in cytofluorometry. Histochemistry 40;59-67, 1974.

9. Fujita, S.: Analysis of cytokinetics by means of Feulgen cytofluorometry combined with ${ }^{3} \mathrm{H}-$ thymidine autoradiography. Expll. Cell Res. 88; 395-401, 1974.

10. Fukuda, M., Isemura, T., Maruo, N., Nakanishi, K. and Fujita, S.: Cytofluorometric measurement of contents of nuclear DNA and intracellular porphyrin converted from heme or hemoglobin on a single erythroid cell. Acta histochem. cytochem. 8; 331-341, 1975.

11. Fukuda, M., Nakanishi, K., Sawamura, I. and Fujita, S.: Standardization of the post-irradiation method to eliminate primary fluorescence in cytofluorometry. Histochemistry $52 ; 119$ 127, 1977.

12. Fukuda, M., Maruo, N., Isemura, T., Böhm, N. and Fujita, S.: Cytofluorometric analysis of cell proliferation and differentiation of the human erythroblasts. Histochemistry 52; 317-327, 1977.

13. Fukuda, M., Isemura, T., Maruo, N., Nakanishi, K., Böhm, N. and Fujita, S.: Cytofluorometric quantitation of the hemoglobin and DNA contents of a single erythroid cell. Acta histochem. cytochem. 10; 443-452, 1977.

14. Fukuda, M., Nakanishi, K. and Fujita, S.: Multi-colour fluorescence method in cytofluorometry. Acta histochem. cytochem. 12; 257-272, 1979. 
15. Fukuda, M., Tsuchihashi, Y., Takamatsu, T., Nakanishi, K. and Fujita, S.: Fluorescence fading and stabilization in cytofluorometry. Histochemistry $65 ; 269-276,1980$.

16. Hale, A. J. and Wilson, S. J.: The deoxyribonucleic acid content of leucocytes in normal and in leukaemic human blood. J. Pathol. Bacteriol. 77; 605-614, 1959.

17. Hale, A. J. and Cooper, E. H.: DNA synthesis in infectious mononucleosis and acute leukemia. Acta haemat. 29; 257-266, 1963.

18. Lampert, F.: Nuclear dry weight, DNA-content and chromosomes in acute childhood leukemia. Virchows Arch. B. Zellpathol. 1; 31-48, 1968.

19. Queisser, U., Olischläger, A., Queisser, W. and Heimpel, H.: Cell proliferation in the preleukemic phase of acute leukemia. A cytophotometric and autoradiographic study. Acta haemat. 47; 21-32, 1972.

20. Sharma, A. K.: Trichloracetic acid and Feulgen staining. Nalure 167; 441-442, 1951.

21. Shimazaki, C., Nakanishi, S., Haruyama, H., Isemura, T., Nakagawa, M. and Ijichi, H.: Cytokinetic analysis of leukemic cells by Feulgen cytofluorometry combined with ${ }^{3} \mathrm{H}$-thymidine autoradiography. Acta haematol. Jap. 45; 641-645, 1982.

22. Takamatsu, T., Tegoshi, K., Matsumoto, Y., Maekawa, J., Nakanishi, K., Fukuda, M., Fujita, S., Tanaka, T. and Sawada, T.: A case of fluminant myelogenous leukemia with two different stem line sub-populations; Cytofluorometric quantification of nuclear DNA of tissue-infiltrating leukemic cells. J. Kyoto Pref. Univ. Med. 88; 1273-1281, 1979.

23. Takamatsu, T., Nakanishi, K., Onouchi, Z., Fukuda, M. and Fujita, S.: Nonspecific ("pseudoplasmal") dye-binding in the Feulgen nuclear stain and its blocking by azocarmin G. Histochemistry 66; 169-180, 1980.

24. Takamatsu, T., Nakanishi, K., Fukuda, M. and Fujita, S.: Cytofluorometry on cells isolated from paraffin sections after blocking of the background fluorescence by azocarmin G. Histochemistry 71; 161-170, 1981.

25. Wickramasinghe, S. N., Cooper, E. H. and Chalmes, D. G.: A study of erythropoiesis by combined morphologic, quantitative cytochemical and autoradiographic methods; Normal human bone marrow, Vitamin $\mathrm{B}_{12}$ deficiency and iron deficiency anemia. Blood 31; 304-313, 1968.

26. Yoshida, Y.: Quantitative cytochemical studies of deoxyribonucleic acid in hemopoietic cells; 2. Cytochemical population analysis of the DNA content in human leukemia cells. Acta haematol. Jap. 32; 181-195, 1969. 